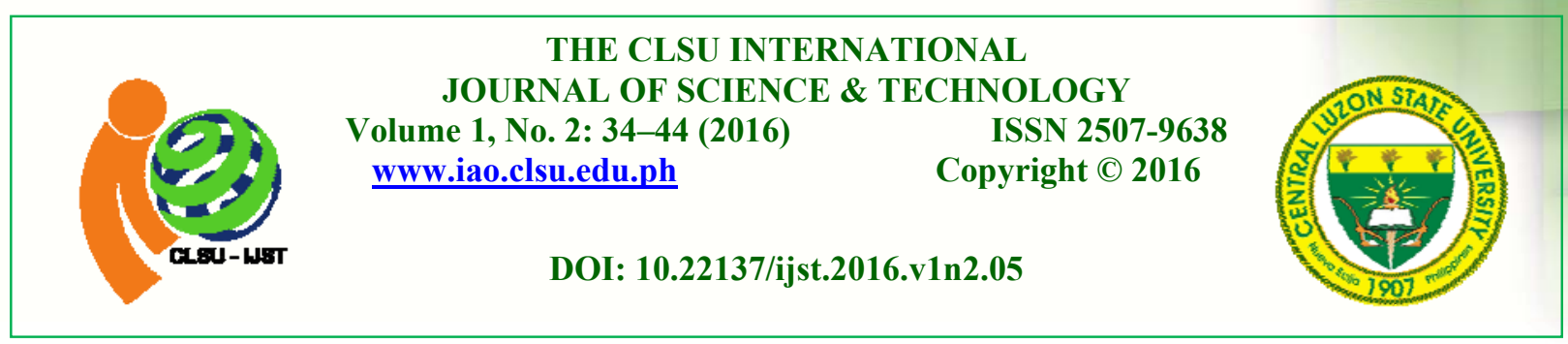

\title{
Assessment of Fisheries Governance: The Case of the Barangay Fisheries and Aquatic Resources Management Council (BFARMC) Empowerment in Tadlac, Los Baños Laguna
}

\author{
Cynthia V. Almazan ${ }^{1}$ and Danilo Vargas ${ }^{2}$
}

${ }^{1}$ Philippine Council for Agriculture, Aquatic and Natural Resources Research and Development, ${ }^{2}$ Central Luzon State University

Email for correspondence: calmazan2002@yahoo.com; danilovargas062@gmail.com

Submitted 20 September 2016, Accepted 26 September 2016, Published online 31 December 2016

\begin{abstract}
The study aimed to assess how the Barangay Fisheries and Aquatic Resources Management (BFARMC) in Tadlac, Los Baños, Laguna were empowered. A total of thirty members of BFARMC in Tadlac were interviewed. The Philippine governance of the fishery resources has undergone several paradigm shifts with several policies formulated to involve fisherfolk in resource management. One of these policies is the institutionalization of the fisheries management known as the Fisheries Aquatic Resources Management Council. The case of Tadlac BFARMC shows different issues in terms of motivation, attitudes, leadership, communication, coordination, members' participation, livelihood, and most of all, empowerment. The lack of budgetary support for the activities of BFARMC is one of the major struggles of the leadership. In addition, the lack of support from the present barangay administration added to the problems in communication, interaction, and coordination of the leaders to its members and within/among the members. These problems had caused chaos in the BFAMRC. Most of the members know that the ultimate goals of the council will benefit them, but without the financial and technical support from the Local Government Unit, specifically the barangay and municipal level, members will not be empowered. Recommendations were formulated to address the different issues in the Tadlac BFARMC. The most significant issue that needs immediate remedy is to guarantee that implementation and effectiveness of BFARMC's policies, laws, and programs will uplift the lives of the fisherfolk.
\end{abstract}

Keywords: Empowerment, fisherfolk, BFARMC, Tadlac

\section{INTRODUCTION}

The Philippines is one of the world's largest archipelagos consisting of 7,107 islands with an estimated $36,000 \mathrm{~km}$ of coastline with a total territorial water area of 2.2 million sq. $\mathrm{km}$ of which 266,000 sq. $\mathrm{km}$ is coastal water and 1.9 million sq. $\mathrm{km}$ is oceanic (World Fishing and 
Aquaculture n.d.). Moreover, the country is one of the largest producers of fishery products in the world, ranking eighth in 2007 world total fishery production (Verstralen et al. 2004.). Total Philippine fishery production in 2011 was registered at 4.98 million metric tons valued at PHP 225 million (BAS 2016). Of which, annual harvest is around 1.04 million tons from commercial fisheries (PHP 59 million), 1.33 million tons (PHP 80 million) from municipal fisheries, and 2.61 million tons (PHP 86 million) from aquaculture. For the last three decades, fisheries production shifted from capture fisheries (commercial and municipal) to aquaculture. In the 1980s, commercial fisheries contributed to the bulk of fish production in the country with approximately $51 \%$ average contribution, while municipal fisheries contributed $26 \%$ and $23 \%$ from aquaculture.

In the 1990 s, contribution of the sectors were almost equal, $37 \%$ from commercial fisheries, $31 \%$ from municipal fisheries, and 32\% from aquaculture. In 2011, the aquaculture industry became the major source of fish supply of the country. Its contribution to fish production accounted for $52 \%$, while municipal fisheries contributed $27 \%$ and commercial fisheries went down to $21 \%$.

Aquaculture was introduced in the Philippines as early as the $14^{\text {th }}$ century. Its importance was recognized only in 1940s when total production was registered at 20,000 tons (Yap 1999). From 1980 to 2009, fish production from aquaculture grew at an average rate of $8.53 \%$ per year (BAS 2010). Aquaculture provides employment for around 26,000 people in 2005 . In the Philippine's Medium Term Development Plan for 2004 to 2010, aquaculture has been identified as a sector for increased growth for job creation in support of the country's drive towards economic development (Lopez 2006). It is perceived that aquaculture will absorb the country's ever growing demand for fish and making it potentially the most important contributor to the country's food security and poverty alleviation agenda (Lopez 2006). The shift of production from capture fisheries to aquaculture can be attributed to the laws/regulations and programs of the Philippine government to reduce the impact of fishing on the environment, particularly in reducing pressure on marine capture fisheries to retain the coral reef fishery diversity (Lopez 2006).

Laguna Lake or Laguna de Bay is the largest lake in the Philippines and among the largest in Southeast Asia. It serves as catchment of an expansive and environmentally important watershed. The Laguna Lake Region is inhabited by a fast growing population, many of whom are highly dependent on the natural resources of the lake for their livelihood and daily needs. Aquaculture is one of the various economic uses of Laguna Lake. Rapid aquaculture development has occurred in the area since the discovery that some fish species can be grown in controlled environments in the lake, including those that are not native to its waters (Israel 2007). However, Laguna Lake is also threatened with household and industrial pollution (Greenpeace 2010).

Aside from pollution, the lake is faced with several problems. These problems can be categorized into technical, production, economic, social, institutional, and environmental. Some of the environmental problems brought about by the proliferation of fish pens in the lake, such as the algal bloom which causes fish mortality or fish kill as stocks die of asphyxiation due to oxygen depletion. Water hyacinths, fish pens, and fish cages had caused various problems like fish mortality, destruction of pen and cage structures, and obstruction of navigation. Aquaculture also resulted to invasion of alien species particularly janitor fish of late, and today the proliferation of knife fish that are predating on the native fishes in the lake. This fish destroys nets and competes for natural food and living space with cultured species. There is also a problem with fish diseases that cause fish mortality or fish kill which in turn reduce the viability of aquaculture operations (Israel 2007). The governance of Laguna Lake has been institutionalized to address the above mentioned problems. This study will look into how the fisherfolk in Laguna Lake were empowered to govern and manage the lake resources.

Vol. 1 No. 2 (December 2016), ISSN: 2507-9, DOI: 10.22137/ijst.2016.v1n2.05 


\section{Conceptual Paradigm}

This study focuses on the assessment of the empowerment of the BFARMC in Barangay Tadlac, Los Baños, Laguna. Using the systems theory in analyzing an organization, the assessment criteria used in the study is shown in Figure 1. There are several laws, policies, and programs involved in the management, conservation, and protection of the Philippines fishery resources. These laws, policies, and programs are the guiding principles in the operationalization of BFARMCs in the country. The framework was the basis for making some policy recommendations in order to empower BFARMC to sustain programs and activities on resources management, conservation, and protection. The empowerment of BFARMC was assessed using individual variables such as motivation and attitude and organizational variables like leadership, resources, communication, interaction, coordination, and policy. Empowered BFARMC is reflective of the degree of participation of members in program planning, implementation, monitoring and evaluation. The degree of participation of members in policy formulation and implementation, degree of participation of members in the management and control of fisheries and aquatic resources and organizational variables such as government-private participation are equally important. Impacts of BFARMCs include fisherfolk access, use and control of resources, equitable distribution of economic benefits, and overall well-being of fisherfolk, community, and coastal resources.

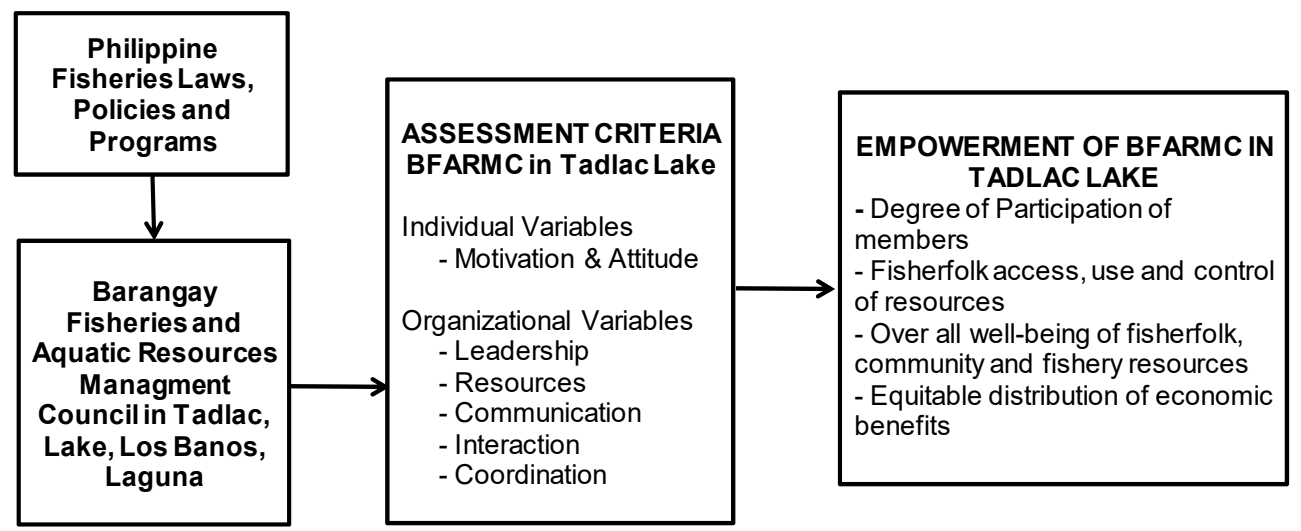

Figure 1 Conceptual Paradigm (Variables are adapted from Bondoc, L.G., 2005 and De Jesus et.al. 2008)

\section{METHODS AND MATERIALS}

This research used the case study analysis. Due to time constraints, this study is limited to using the descriptive case study focusing on the members and officers of the Tadlac BFARMC. The study was conducted in Barangay Tadlac, Los Baños, Laguna. The study area was chosen due to the proximity of the area in Laguna de Bay and Alligator Lake. It was conducted last July to August 2016. The listing of members of BFARMCs in Los Baños, Laguna was used as the sampling frame for this study. Random sampling was used; whenever the fisherfolk was available to be interviewed, they formed part of the respondents. In Tadlac, there are a total of 177 members of BFARMC (N). A total of 30 fisherfolk (n) were interviewed. Three types of data collection techniques are used in this study; these are desk research, case study, survey, and key informants interview. An interview schedule was used for this research. Questionnaires were developed for the members of BFARMC in Barangay Tadlac, Los Baños, Laguna. An interview schedule for key informants was also formulated. The officials of the BFARMCs served as the key informants. 


\section{RESULTS AND DISCUSSION}

The governance of the fishery resources in the Philippines underwent several paradigm shifts. Governance had shifted from resources allocation, local empowerment, and conservation to food, poverty alleviation, and sustainability. Several policies have been formulated to involve fisherfolk in resource management. With the change in governance, fishery resource management had been devolved to the LGUs with the involvement of different fisherfolk, which are now legally organized and institutionalized into FARMC and at the barangay level, BFARMC. Decentralization, however, falls short of devolution of powers to local communities but it opens opportunities for fisherfolk to engage with governance of fishery resources.

The case of Tadlac BFARMC is not a representative of the general situation of barangay level FARMCs in the country but it shows the different issues in terms of motivation, attitudes, leadership, communication, coordination, members' participation, livelihood, and most of all, empowerment.

\section{Overview of the BFARMC in Barangay Tadlac}

The enactment of Executive Order No. 240 and the Fisheries Code has led to the creation of the Barangay Tadlac FARMC. The BFARMC in Tadlac is composed of members representing the fisherfolk, the Barangay Development Council, the Chairperson of the Municipal Committee on Agriculture and Fisheries, and a non-government organizationbased in the locality. The set of officers include a Chairperson, a Vice Chairperson, Secretary, Treasurer, Auditor, Public Relations Officer, and Sergeant-at-Arms.

The Tadlac BFARMC's initial budgetary allocation was in the form of donation. The Filipino communities in Thailand, the Barangay Tadlac Resource Management Council, with Ugnayan sa Los Baños (ULB), an NGO working in the area, donated a total amount of PHP 50,000 (US \$1,100). A fish landing in the lake was constructed using the donated funds. Such fish landing also serves as a multi-purpose facility for meetings and picnics. The LGU of Los Baños supports the Tadlac's BFARMC through the allocation of the fish pen fee share its gets from the LLDA. The share from fish pen fee is used for the various projects of the BFARMC. Such sharing of fees is covered by Municipal Ordinance 2001-10, which specifically allots $10 \%$ each to the FARMCs of the five lakeshore barangays, one of which is Barangay Tadlac (Almero-Peña and Erasga 2012).

BFARMC such as in Barangay Tadlac receives institutional development support from LLDA and other government agencies in the form of trainings and seminars on environmental monitoring, stewardship, management, and project development. Likewise, the Bureau of Fisheries and Aquatic Resources (BFAR) gives paralegal training leading to the deputation of FARMC members as fish wardens. Other supports coming from BFAR are the provision of fingerlings for lake seeding and food allowances for volunteers in lake clean-up activities, such as the manual harvesting of water hyacinth, removal of abandoned fish pen and fish cage materials, and the collection of organic and inorganic debris (Almero-Peña and Erasga 2012).

\section{Barangay Tadlac Fisheries and Aquatic Resources Management Council}

A total of thirty (30) BFARMC members were interviewed. Most of the respondents are male, fall under 41-50 years of age, and are married. Almost half of the respondents have

Vol. 1 No. 2 (December 2016), ISSN: 2507-9, DOI: 10.22137/ijst.2016.v1n2.05 
elementary and secondary education. Main source of income of most of the respondents is fishing, while other sources of income includes fishpen/fishcage, farming, fish/vegetable vending, construction work, and painting.

Majority of the respondents' motivation in joining BFARMC was to secure tilapia fingerlings and fish nets. For others, protection of the lake and enforcement of fishery laws motivated them to join the organization. They were encouraged by LLDA and BFAR to join the organization. There were few who were motivated by their neighbors and other members and officers of BFARMC. There were some respondents who are motivated to join BFARMC to benefit from it even though they lacked information on their role in joining the organization

Respondents were asked on their perception on the need to have BFARMC in their area. About half of the respondents agreed that BFARMC helps resolve conflicts in the community. However, there were few who disagreed on it and were uncertain if BFARMC is needed to resolve conflicts. Majority of the respondents perceived that BFARMC is needed to empower fisherfolk, to enforce policies/laws and fishery programs, and to plan and implement fishery policy/laws and programs. All of the respondents believed that collective responsibility is a major characteristic of any BFARMC and active involvement of members are a prerequisite for participation.

Respondents were asked on their perception on the benefits they are getting from joining the BFARMC. More than half of the respondents strongly disagreed that they are getting additional income from their membership to BFARMC's livelihood programs, while few believed that they were getting an additional income from it. They reported that the fingerlings and fish nets given to them had helped them in their livelihood. More than half of them felt a sense of belongingness from the BFARMC and sense of self-esteem, achievement, and respect for others.

More than half of the respondents perceived that BFARMC is an important factor in the conservation of Laguna Lake. They have reported that the objectives and policies of BFARMC are geared towards the betterment of managing the lake resources. Despite this notion, about half of the respondents were not amenable that BFARMC had helped them improve their skills and knowledge in the conservation and management of the lake. In addition, some of the respondents did not believe that BFARMC is important for the conservation of the lake and in the improvement of their skills and knowledge, while few were uncertain about it. Some of the respondents were uncertain if the establishment of BFARMC contributed more benefits to the fisherfolk. There were few of the respondents who believed that BFARMC contributed more benefits to fisherfolk. Some of the respondents did not believe that BFARMC significantly contributed in the improvement of their family's income, while few were uncertain about it. Few of them perceived that BFARMC has significantly contributed to an improvement in their income. More than half of the respondents were uncertain if BFARMC has provided members greater and better access to the resources and only a few believed such statement.

Respondents were asked about their perception about the BFARMC's leadership. Most of the respondents reported that BFARMC's leadership was not stable for the past five years. Some of them even reported that the election last two years ago was abruptly conducted, and most of the members were not informed about it. Respondents also reported that the present leadership of BFARMC is weak and inactive. Because of these, most of them reported that the BFARMC's leaders were not able to lead members to achieve its goal. Majority of them also reported that there had been problems with the leadership of BFARMC.

Respondents were asked of their perception on the leadership style of BFARMC officers. Most of the respondents reported that the leadership style of BFARMC officers is authoritarian.

Vol. 1 No. 2 (December 2016), ISSN: 2507-9, DOI: 10.22137/ijst.2016.v1n2.05 
Most of the time, the leaders attend meetings with the integrated FARMCs in Sta. Cruz, Laguna and in MFARMC meetings in Los Baños, Laguna. Members are only informed about results of the meetings. Some of them even reported that they were not informed about what had transpired in the meetings that were attended by the officers.

Respondents were asked about the resources provided by BFARMC. All of the respondents reported that there were no equipment/facilities provided by BFARMC. Majority reported that BFAMRC was not able to provide technical know-how to its members, livelihood trainings, and alternative livelihood.

Majority of the respondents reported that the form of communication used in the BFARMC is from officer to members only. This confirms earlier findings that the leadership style is authoritarian. Most of the respondents also reported that for two years they have had only one meeting which was conducted recently. Moreover, some of the male respondents reported that the meeting was about the fish processing livelihood program and they complained that such livelihood program was for women-members of BFARMC.

Respondents were asked about their perception on the interaction of BFARMC's officer and members. Majority of the respondents reported that BFARMC does not consult its members through meetings/conference to discuss matters pertaining to the organization's programs and policy development. Whenever there are meetings, more or less half of members are attending.

Perceptions about enforcement of municipal ordinances were solicited from the respondents. Most of the respondents reported that BFAMRC is not enforcing municipal ordinances with regards to fishing permit requirements, while some reported that it is partly enforced. Majority of the respondents reported that enforcing the municipal ordinances regarding issuance of boat license to operate is not enforced, while there were few reported that it is partly enforced. Most of the respondents mentioned that they are not aware of any ordinances with regards to the size of fish mesh net and other active fishing gears. The use of poisonous substances is not practice in the lake; hence they lacked knowledge about its enforcement.

With regards to respondents' participation in the different BFARMC activities, there were very few who were participating in the planning, implementing, and monitoring and evaluation activities of the BFARMC. Majority of the respondents were not engaged in these activities. The non-participation of majority of the respondents is due to lack of such activities being conducted by the BFARMC. Respondents reported that they had participated in the activities of the BFARMC conducted in the earlier years. In addition, majority of the respondents were inactive in participating in planning/formulation of ordinances and policies.

With regards to respondents' use, access, and control of the lake, all of them strongly agreed that they have access to the use of the lake. They were allowed to fish in the lake and for those who have permits for fish pens/fish cages, they are still allowed to maintain their pens/cages but are no longer allowed to add more units. Majority of them strongly agreed that they are using the lake in a sustainable manner.

Respondents were asked on their perception about the improvement of the overall wellbeing of the communities. All of the respondents strongly disagreed that the BFARMC's programs and policies will threaten their jobs and laws to protect the environment will limit their choices and personal freedom. They perceived that they can fish in the lake whenever they want and they can continue using it for culturing tilapia.

Vol. 1 No. 2 (December 2016), ISSN: 2507-9, DOI: 10.22137/ijst.2016.v1n2.05 
Majority of them perceived that conservation practices contribute to the quality of life in their community. Most of the respondents reported that the conservation practices being practiced in the lake include collection of solid waste and rehabilitation of rivers. Majority of them reported that this is being done on their personal capacity and is not related to the activities of the BFARMC. There were few who reported that they no longer care if there is solid waste in the lake. For them, it is useless to clean the lake if the communities are not engaging on it. Majority of them strongly disagreed that the quality of water from the lake is improving. Majority are not amenable that they could benefit more after the adoption of programs and policies along the lake.

Majority of the respondents perceived that they are not getting enough income from the use of the lake, and they cannot send their children to school from the income they are getting from the use of the lake. Most of them reported that they need another job to be able to sustain their financial needs, and majority of them were not satisfied with what they are earning from the use of the lake. Majority of the respondents perceived that the most critical problem that affects the lake is the solid waste disposal of the communities. Other critical problems reported by most of the respondents are water pollution, proliferation of invasive species, and the proposed mega-dike that will affect their livelihood in the lake. There were only few of the respondents that mentioned problems that are related to BFARMC. These include no regular meetings being conducted, no unity among members and officers, and lack of good leadership.

Overall perception about BFARMC was also solicited from the respondents. They were asked if they were empowered. They also rated the BFARMC on the achievement of its goals. Majority of respondents were unsure if BFARMC had empowered the fisherfolk in their community. More than half of them reported that BFARMC had partly achieved its objectives. A few reported that BFARMC were not able to achieve its objectives.

\section{Key Informants Interview}

Four BFARMC officials were interviewed as key informants. Most of the key informants were not sure about when the BFARMC in the Barangay Tadlac was established. What they are sure of is that the LLDA, BFAR, and the Los Baños Municipal Office have coordinated for its establishment.

Key informants were asked about their perception on the motivation of fisherfolks to join the BFARMC. They perceived that fisherfolk are motivated on the livelihood trainings/seminars that BFARMC can provide, additional livelihood for members, protection of Laguna Lake, and empowerment of the fisherfolk.

Key informants reported that BFARMC's role in their area includes assistance in the preparation of Barangay/Municipal Development Plan and advice to the Sangguniang Barangay on fishery matters. As officers, they reported that they are involved in these tasks.

When asked about their perception on the need of BFARMC in their area, the key informants have different views. One of the key informants perceived that BFARMC is important to help resolve conflicts in the community and to plan and implement laws/policies and fishery programs. Two of the key informants believe that there is a need for BFARMC to empower fisherfolks in their area, collective responsibility is its major characteristic, and active involvement of members is a prerequisite for participation.

Key informants were also asked on their perception on the criteria in choosing a leader for the BFARMC. All of them agreed that a leader visionary believes that he/she can manage an

Vol. 1 No. 2 (December 2016), ISSN: 2507-9, DOI: 10.22137/ijst.2016.v1n2.05 
organization and will be able to organize people very well, a leader inspires confidence in others and draws out the trust and best effort to complete the task well. They also believe that a leader must be able to think fast and make good decisions. He/she must be loyal and dedicated and a role model of hard work.

Based from the key informants, financial support for the operation of BFARMC comes from a percentage of the permits for fishpen/fishcage collected. This is being given yearly. Aside from this, there is no other financial support given for the BFARMC. One of the key informants reported that they will have an upcoming project in 2017, i.e. Bottoms-Ups Budget. One key informant also reported that the Bantay Dagat Enforcers were not even given identification cards, uniforms, and budget; hence it is difficult for them to enforce fishery laws. Aside from very limited budgetary support, there is lack of support from the present Barangay administration. Key informants reported that due to personal differences with the Barangay officials, they had difficulty getting support from the Barangay. Budgetary support and other forms of support from the Barangay administration are crucial in BFARMC's implementation of activities, such as provision of livelihood trainings, livelihood programs, and livelihood for members.

According to one of the key informant, the forms of communication used in the BFARMC are from officer to members, from members to officers, and within members themselves. However, other key informants reported that communication flow is from officer to members only. This usually involves the BFARMC officials attending meetings with higher management bodies like MFARMC and Laguna Integrated FARMC.

Key informant reported that the BFARMC is consulting its members through meetings/conferences to be able to discuss matters pertaining to the organization's programs and policy development. However, other key informants strongly disagree about this. They reported that with the present leadership of BFARMC, they have only conducted a meeting with members once. The said meeting was conducted only this year. One of the key informants reported that members are active only to participate in meetings if they knew that they will gain something from it.

BFARMC's coordination with other agencies and entities is very limited. Despite this, the BFARMC officers are active in participating in meetings with higher management levels. In terms of coordination techniques, the key informants have rated BFARMC to have a poor performance.

In terms of enforcement of laws, key informants reported that the fishing permit requirement is partly being enforced in their area. However, they reported that other laws, i.e. securing boat license to operate, prohibition of the use of fine mesh nets, and poisonous substances, are not enforced in their area. They reported that use of poisonous substances is not practiced in their area and they are not aware of any regulation about the size of mesh that is allowed by law.

Problems encountered by BFARMC include solid waste management which is polluting the lake, factories that are dumping toxic substances in the lake, occasional fish kills, presence of resorts that are discarding water with chlorine in the lake, lack of support from the Barangay administration, limited financial support, low participation of members in activities, and weak coordination.

In terms of level of participation of member in Bantay Dagat Programs such as planning, implementation, monitoring and evaluation, all of the key informants rated it to be very low. Only one key informant reported that they are active in policy development. Other key informants reported that members are not actively participating in BFARMC policy development activities.

Vol. 1 No. 2 (December 2016), ISSN: 2507-9, DOI: 10.22137/ijst.2016.v1n2.05 
Most of the key informants, believed that fishery resources are not used sustainably. They reported that even without the presence of BFARMC, they can access and use lake resources. However, they believed that BFARMC provides a mechanism to control the use and access of the lake.

In terms of benefits sharing, which are only the tilapia fingerlings and fry and fish nets from BFAR, it is difficult to have an equal distribution because the fingerlings and fish nets are limited and the frequency of provision is very seldom. In terms of economic benefits, i.e. fish catch and income from fishing, before and after the formation of BFARMC, key informants reported that benefits are better before compared to the present. Regarding the living conditions of the members, key informants are uncertain about it and did not give any comments.

When asked if the changes happening in their community can be attributed to BFARMC, all of the key informants answered "no." On the other hand, they reported that pollution is the most critical problem with regards to fisheries and aquatic resources management. In addition, they have stated that BFARMC will not be able to solve this problem alone.

One key informant believed that BFARMC was empowered; the rest say otherwise. One key informant reported that the objectives of the BFARMC were achieved, while the rest reported that objectives were not achieved.

\section{RECOMMENDATION}

The lack of sustainable support for the activities of BFARMC is one of the major struggles of the leadership. Specifically, the lack of support from the present barangay administration added to the problems in communication, interaction, and coordination of the leaders to its members and within/among the members. These problems had caused chaos in the BFARMC. Most of the members know that the ultimate goals of the Council will benefit them, but without the support from LGU specifically the barangay and municipal level (financially and technically), members will not be empowered.

The present status of BFARMC in Tadlac has shown that in the lowest management body of FARMCs, issues and problems exist due to the lack of a sustainable support from BFAR, MFARMC, and the LGU. This dilemma in BFARMC's management needs to be reviewed to be able to encourage coordination, monitoring, and evaluation of its programs and activities thereby fishery resources could be managed accordingly. Lastly, the most significant challenge is to guarantee that implementation and effectiveness of BFARMC's policies, laws, and programs will uplift the lives of the fisherfolk.

Taking into account the issues and problems faced by the BFARMC in Tadlac, Los Baños, Laguna, the following recommendations are suggested to address these issues and to empower the said Council.

To ensure that fisherfolk organizations, such as BFARMC, are equipped with the skills to continue the programs and activities of the council, trainings and skills development initiatives should continue. Leadership training must be conducted to equip present and future leaders of BFARMC with skills that will empower fisherfolk. Aside from leadership training, livelihood trainings that are lake-dependent and non-lake-dependent should be provided so that fisherfolk will not mainly depend on the lake resources for their livelihood, hence minimize resource use. There are issues and problems with regards to management of the fishery resource that were found in the study. However, the primary problem is the marginalization of the fisherfolk. Again, other sources of

Vol. 1 No. 2 (December 2016), ISSN: 2507-9, DOI: 10.22137/ijst.2016.v1n2.05 
livelihood can be provided to uplift the overall well-being and living conditions of the fisherfolk. Unless they will be given other opportunities to earn income, their dependency on the lake will continue and they may not be able to uplift their status.

Programs to increase awareness regarding FARMC particularly BFARMC should be established. Officers and members should be reoriented with the mission, vision, objectives, expected output, programs, and activities of FARMC as a whole and BFARMC as the smallest body of the Council. Awareness building on the need for BFARMC in the area should also be initiated. Information and education campaigns on the different municipal and barangay ordinances in relation to fishery resource management should be done. This will strengthen the enforcement of laws and will increase fisherfolk's participation in its implementation and enforcement in the area.

The BFARMC should be empowered to network and link with other BFARMCs in the province, NGOs, LGUs, concerned government agencies and units, and private sectors. Such networking and linking will help BFARMC in terms of funding and technical assistance. BFARMC should submit annual plans which can be divided into quarterly and/or monthly plans of activities to ensure that there is interaction, coordination, and communication within and among members of the organization. Monitoring of the said activities of the BFARMC should be conducted regularly by MFARMCs to ensure that issues and problems are being addressed accordingly.

The proximity of the University of the Philippines in the area should be maximized. Environmental education can be conducted every time a new initiative is undertaken. Professors and researchers of UPLB can be tapped as resource speakers for this activity. This will help instill in the community the importance of taking care of the environment. This will help fisherfolk to advocate for the good of the environment specifically, the Laguna Lake.

\section{REFERENCES}

Almero-Peña, E.B. and M. Erasga. 2012. "Multistakeholders Efforts for the Sustainable Management of Tadlac Lake, Philippines." International Partnership for Sayotoma Partnership Website. $\quad$ http://satoyama-initiative.org/en/multi-stakeholders-efforts-for-the-sustainablemanagement-of-tadlac-lake-the-philippines-2/

Bureau of Agricultural Statistics. 2016. "CountrySTAT Philippines." http://countrystat.psa.gov.ph/?cont=10\&pageid=1\&ma=C70PNVPP

De Jesus, C.D., L.G. Bondoc, and C.V. Almazan. 2008. Executive order 240 (The FARMC): How Far Does It Go? (unpublished)

Israel, D. 2007. "The Current State of Aquaculture in Laguna de Bay". PIDS Discussion Paper Series 2007-20

Greenpeace. $2010 . \quad$ "Laguna Lake." Greenpeace http://www.greenpeace.org/seasia/ph/What-we-do/Toxics/Water-Patrol/The-problem/Laguna-Lake/

Lopez, D.A. 2006. "Sustainable Development and Trends in the Philippine Aquaculture." Country paper presented at the FFTC-RCA International Workshop on Innovative Technologies for Eco-

Vol. 1 No. 2 (December 2016), ISSN: 2507-9, DOI: 10.22137/ijst.2016.v1n2.05 
friendly Fish Farm Management and Production of Safe Aquaculture Foods, Denpasar, Bali, Indonesia, 04-08 December.

World Fishing and Aquaculture. n.d. "New Horizons" Philippines. http://www.worldfishing.net/features/new-horizons/philippines3

Verstralen, K.M., L.N. Lenselink, R.Ramirez, M. Wilkie, and J.P. Johnson. 2004. Participatory Landing Site Development for Artisanal Fisheries Livelihoods: Users' Manual. Rome: FAO. ftp://ftp.fao.org/docrep/fao/012/i0989e/i0989e04b.pdf 